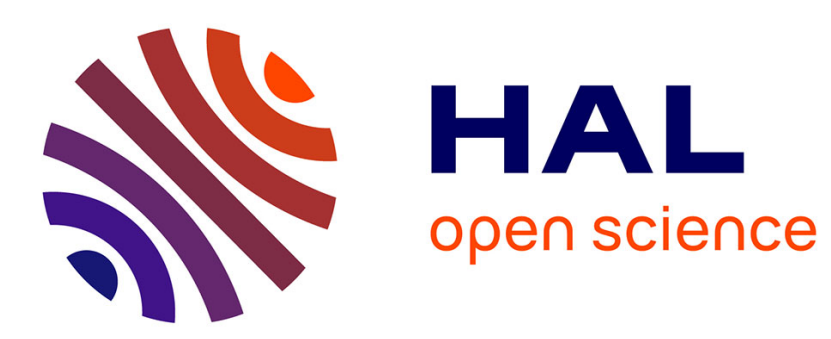

\title{
Confinement effects at nanoscale in natural rubber composites: Influence on macroscopic properties
}

\author{
Bindu Patanair, Sabu Thomas, V Abitha, Allisson Saiter
}

\section{To cite this version:}

Bindu Patanair, Sabu Thomas, V Abitha, Allisson Saiter. Confinement effects at nanoscale in natural rubber composites: Influence on macroscopic properties. Journal of Applied Polymer Science, 2020, pp.49838. 10.1002/app.49838 . hal-02925922

\section{HAL Id: hal-02925922 \\ https://hal.science/hal-02925922}

Submitted on 18 Feb 2021

HAL is a multi-disciplinary open access archive for the deposit and dissemination of scientific research documents, whether they are published or not. The documents may come from teaching and research institutions in France or abroad, or from public or private research centers.
L'archive ouverte pluridisciplinaire HAL, est destinée au dépôt et à la diffusion de documents scientifiques de niveau recherche, publiés ou non, émanant des établissements d'enseignement et de recherche français ou étrangers, des laboratoires publics ou privés. 


\title{
Confinement Effects at Nanoscale in Natural Rubber Composites: Influence on Macroscopic Properties
}

\author{
Bindu Patanair ${ }^{\mathrm{a}, \mathrm{b}}$, Sabu Thomas ${ }^{\mathrm{a}}$, Abitha V. K ${ }^{\mathrm{a}}$, Allisson Saiter-Fourcin ${ }^{\mathrm{b}, *}$ \\ a: School of Chemical Sciences, School of Energy Materials and International and Inter- \\ University Centre for Nanoscience and Nanotechnology, Mahatma Gandhi University, \\ Priyadarshini Hills P.O, Kottayam, Kerala, India 686560 \\ b: Normandie Univ, UNIROUEN, INSA Rouen, CNRS, GPM, 76000 Rouen, France \\ *Corresponding author. tel: 0033232955086 fax: 0033232955082 \\ E-mail address: allison.saiter@univ-rouen.fr
}

\begin{abstract}
:
The study of molecular level interactions in elastomer composites has got very scant attention even though a large number of studies are going on in this topic. This work embodies the understanding of confinement effects in natural rubber (NR)/ $\mathrm{ZnO}$ composites from micro to nano length scales, and their influence on macroscopic properties of the composites. The interactions between fillers and matrix are characterized from the Donth's approach, which allows estimating the cooperativity size $\mathrm{N}_{\alpha}$ at the glass transition, $\mathrm{N}_{\alpha}$ being directly related to the filler-matrix interactions. The improved properties of NR-nano $\mathrm{ZnO}$ composites can be attributed to microstructural and morphological changes due to nano $\mathrm{ZnO}$ in the NR matrix. A correlation between $\mathrm{N}_{\alpha}$, the constrained volume $\mathrm{C}_{\mathrm{v}}$ and the thickness of immobilized polymer chains $\chi_{\mathrm{m}}$ at the glass transition has also been established. Thus, this work proves that the Donth's approach is a powerful probe to estimate the enhance of mechanical properties in nanocomposites from calorimetric investigations.
\end{abstract}

Keywords: Natural rubber, Composites, Mechanical Properties, Glass transition, Cooperativity length, Confinement, Donth's approach 


\section{INTRODUCTION}

Elastomers are special kind of amorphous polymers containing soft and flexible chains. They have low modulus and strength compared to other types of polymers, and hence the inclusion of fillers is essential for obtaining substantial improvements in the physical and mechanical properties. The effects of various types of fillers in the micrometer size range such as carbon black, calcium carbonate, glass fibers, talc, expanded graphite (EG) etc. on elastomer matrix properties are widely studied [1]. However, optimal performance of the final micro composite could be achieved at higher filler concentrations. This causes the viscosity enhancement, and thus creates difficulties in the processing. Nanofillers offer an ultimate solution to these problems due to their high specific surface area and hence fewer quantities are required. It has been observed that the addition of just a very small quantity of nano-sized fillers like carbon nanotubes (CNTs), graphene, clay, polyhedral oligomericsilsequioxane (POSS) etc. is sufficient for improving the properties of virgin polymers to a great extent when compared to micro sized fillers [2-4]. Novel engineered materials from natural rubber (NR) with new fibrous nanofillers with improved barrier properties were prepared for use in tire inner-liner applications [5] and the composites of polyethylene (PE) with NR has higher level of biodegradability under environmental conditions [6]. Moreover, the high surface to volume ratio and other superior properties of nanoparticles help the stress transfer from the matrix to the reinforcement, and assume good adhesion at the interface. But still both micro as well as nano composites are not devoid of deterioration in properties and structural defects. This depends on the mode of filler dispersion in the matrices [7-10] and therefore modification of filler surfaces is often practiced prior to compounding.

Confinement effects of elastomer molecules in composite systems can regulate composite properties and thus their applications $[10,11]$. The orientation of elastomer chains in the presence of micro as well as nanofillers is one of the key factors affecting mechanical properties. In our previous study [12], we proposed a core-shell morphology model and constrained polymer model to explain the effect of constrained polymer chains in the NR-nano $\mathrm{ZnO}$ nanocomposite system. In the current study, the confinement effect due to the size differences of fillers (micro and nano $\mathrm{ZnO}$ ) will be quantified by focusing on the amorphous phase, and by using the Donth's approach [13] from which it is possible to estimate a cooperative rearranging region (CRR) in terms of structural unit number noted $\mathrm{N}_{\alpha}$. $\mathrm{N}_{\alpha}$ represents the number of structural units which move together at the glass transition. Thus, a CRR allows to illustrate the well-known notion of cooperative movement at the glass 
transition. $\mathrm{N}_{\alpha}$ can be calculated from the equation 1 . All the parameters in this equation can be estimated from MT-DSC experiments.

$$
N_{\alpha}=\frac{N_{A}\left[\left(\frac{1}{c_{p, \text { glass }}\left(T_{\alpha}\right)}\right)-\left(\frac{1}{c_{p, \text { liquid }}\left(T_{\alpha}\right)}\right)\right]}{M_{o}(\delta T)^{2}} k_{B} T_{\alpha}^{2}
$$

where $\mathrm{T}_{\alpha}$ is the glass transition temperature (in $\mathrm{K}$ ), $\mathrm{k}_{\mathrm{B}}$ the Boltzmann constant, $\mathrm{C}_{\mathrm{p}}$ the heat capacity at constant pressure (in $\mathrm{J} /(\mathrm{g} . \mathrm{K})$ ), $\mathrm{M}_{0}$ the molar mass of one structural unit $(68.12$ $\mathrm{g} / \mathrm{mol}$ ), and $\delta \mathrm{T}$ (in $\mathrm{K}$ ) the mean temperature fluctuation related to the glass transition temperature of an average CRR. All these quantities are directly extracted from MT-DSC curves. All the details about this extraction are clearly explained in reference [13]. The notion of CRR has been first introduced by Adam and Gibbs [14], which defined this as a subsystem, which can rearrange its configuration to another one independently of its environment. Each CRR presents subsystem having its own glass transition temperature and its own free volume, linked to its own relaxation time. The Donth's approach which allows estimating the CRR size, is based on calorimetric measurements, and has been often used to study the effect of fillers on molecular mobility in nanocomposites [15-20]. It has been proved that this approach allows to characterize the interactions between fillers and matrices, and then to predict if the fillers improve the macroscopic properties for industrial applications. This approach is a powerful way to study and quantify the filler/matrix interactions in composites. As far as we know, this is the first time that this model is applied to quantify the filler/rubber interactions in natural rubber composites, and to understand and better explain why the mechanical properties are enhanced or not.

\section{MATERIALS AND METHODS}

The preparation of $\mathrm{ZnO}$ nanoparticles, its characterization and its composites were described in detail in ref. $[12,21]$. Synthesis of $\mathrm{ZnO}$ nanoparticles from zinc chloride and chitosan is a new synthetic approach [22] and in the present procedure we optimized the reaction conditions to facilitate the formation of $\mathrm{Zn}$-chitosan complex and also to increase the yield of the $\mathrm{ZnO}$ nanoparticles. Since chitosan is a linear polymine with reactive amino groups and hydroxyl groups, and hence can easily form chelates with transition metal ions. In the present reaction, chitosan acts as a chelating agent for $\mathrm{Zn}^{2+}$ ions to form $\mathrm{Zn}-$ chitosan complex. This is an ionexchange method to precipitate $\mathrm{Zn}(\mathrm{OH})_{2}$. By mixing both $5 \%$ solution of $\mathrm{ZnCl}_{2}$ in $1 \%$ acetic acid (ie. $5 \mathrm{~g}$ of $\mathrm{ZnCl}_{2}$ in $100 \mathrm{ml} 1 \%$ acetic acid) with $1 \%$ solution of chitosan in $1 \%$ acetic acid and the whole mixture was stirred for $21 \mathrm{~h}$. After this, stoichiometric amount of $\mathrm{NaOH}(5$ 
\%) was added drop wise to the above reaction mixture with constant stirring. The whole mixture was then allowed to digest for $24 \mathrm{~h}$ at room temperature. During this time, $\mathrm{OH}^{-}$and $\mathrm{Cl}^{-}$ ions were diffused through the medium and white gel-like precipitate of $\mathrm{Zn}(\mathrm{OH})_{2}$ was formed. This was filtered and washed thoroughly with distilled water to remove unreacted chitosan and other by-product like $\mathrm{NaCl}$. This was then dried at $100{ }^{\circ} \mathrm{C}$ and annealed at $550{ }^{\circ} \mathrm{C}$ for $4 \mathrm{~h}$. in a muffle furnace to get $\mathrm{ZnO}$ nanocrystals. The yield of $\mathrm{ZnO}$ nanocrystals obtained by this method is about $90 \%$. In this modified method, the reaction can be carried out under moderate conditions, yield of the product is good and particles of nanometer size $\mathrm{ZnO}$ can be attained.

\section{Preparation of NR/nano ZnO Composites}

Natural rubber (NR) (100 g) was masticated in a two-roll mill; after that, $1 \mathrm{~g}$ (or $1 \mathrm{phr}$ ) of nano $\mathrm{ZnO}$ and $2.5 \mathrm{~g}$ of co-activator stearic acid were added and again masticated. Milling was continued by the successive addition of the accelerators N-cyclohexylbenzothiazole- 2sulphenamide (CBS) (0.6 g) and tetramethyl thiuram disulphide (TMTD) (0.1 g), and the vulcanizing agent sulfur $(2.5 \mathrm{~g})$. The NR composites with varying weight percentages of nano $\mathrm{ZnO}$, viz. 2, and $3 \mathrm{~g}$ (or 2 and $3 \mathrm{phr}$ ), were also prepared in the same manner. In general practice for comparison, $5 \mathrm{~g}$ (or $5 \mathrm{phr}$ ) of micro $\mathrm{ZnO}$ is used as the standard cure activator for $100 \mathrm{~g}$ NR instead of nano $\mathrm{ZnO}$. The weights of all other reactants remain intact. All weights are taken in parts per $100 \mathrm{~g}$ of rubber (phr).

Curing characteristics of the compounded vulcanizate (prepared composites) were tested by using Prescott moving die Rheometer according to the ASTM D 5283 standard at high pressure and temperature $150^{\circ} \mathrm{C}$ for $15 \mathrm{~min}$. All samples were cured as mentioned above and these cured samples were used for further analyses.

The nanocomposites, viz. NR-1 phr nano, NR-2 phr nano and NR-3 phr nano were already characterized by SEM, TEM and AFM [12]. Cryo fractured surface of the samples coated with a thin film of carbon was used for SEM analysis. SEM images were taken with the help of a JEOL 840 analyzer with a W-filament, secondary E-T, and a solid-state backscattered electron detector. Cryo-microtome sliced samples were used for TEM analysis. Cryo-microtome sliced samples of thickness about $100-150 \mathrm{~nm}$ at $-110{ }^{\circ} \mathrm{C}$ were prepared with the help of a Leica Ultracut UCT (Leica Microsystems GmbH, Vienna, Austria) instrument with sharp glass knives. The cryo sections were collected in sucrose solution and directly placed on a copper grid of 300 mesh. TEM was performed with a JEOL 2100, Japan instrument, operated at an accelerating voltage of $200 \mathrm{kV}$. 
The surface morphology of rubber nanocomposites was obtained by AFM, images were taken by using a Veeco di Innova AFM microscope. The samples were kept in phase contrast tapping mode with a frequency of $258 \mathrm{kHz}$ and a scan rate of $1 \mathrm{~Hz}$. The AFM measurements were carried out in air at ambient conditions $\left(25^{\circ} \mathrm{C}\right)$.

The mechanical properties were studied by using a Zwick 1474 Universal testing machine at room temperature as per ASTM D 412 standard. Dumbbell shaped samples were punched out from compression molded sheets (length $\times$ width $\times$ thickness $=120 \times 30 \times 2 \mathrm{~mm}$ ) along the mill direction using a dumbbell die and were used at a testing cross head speed of $500 \mathrm{~mm} / \mathrm{min}$ with the cell load of $1 \mathrm{kN}$. The software, testXpert is used for data processing.

The dynamic mechanic analysis (DMA) was also carried out [12] using NETZSCH DMA 242 machine in the temperature range $-110{ }^{\circ} \mathrm{C}$ to $110{ }^{\circ} \mathrm{C}$, at a heating rate of $2{ }^{\circ} \mathrm{C} / \mathrm{min}$ and three different frequencies 10.00, 1.00 and $0.10 \mathrm{~Hz}$. Rectangular test specimens having sample dimensions $60 \times 10 \times 2 \mathrm{~mm}$ (length $\times$ width $\times$ thickness) were kept in a dual cantilever mode and measurements were performed in air atmosphere. Liquid nitrogen was used as the cooling medium.

Classical (DSC) and modulated temperature differential scanning calorimetry (MT-DSC) experiments were conducted on a thermal analysis instrument heat flow calorimeter (DSC Q100 TA instrument $\left.{ }^{\circledR}\right)$, coupled with a Refrigerated Cooling System (RCS). The experiments were conducted under inert nitrogen atmosphere with a flow rate of $50 \mathrm{ml} / \mathrm{min}$. The apparatus was calibrated for heat flow, temperature and baseline using standard Tzero technology. For temperature and heat flow calibrations, standards as Indium were used. The calibration of the specific heat capacity was carried out using Sapphire as a reference.

The DSC analyses of all the samples were carried out by cooling from $10{ }^{\circ} \mathrm{C}$ down to $-90{ }^{\circ} \mathrm{C}$ at a cooling rate of $5{ }^{\circ} \mathrm{C} / \mathrm{min}$, permitting first to erase the thermal history of the sample (as we started the experiments above the glass transition domain), second to optimize the thermal contact between sample and pan (as the sample is in its rubbery state), and also to follow the temperature ramp in a broad domain. All the MT-DSC analyses were carried out with the following protocol: oscillation amplitude of $1{ }^{\circ} \mathrm{C}$, oscillation period of $120 \mathrm{~s}$ and cooling rate of $0.5{ }^{\circ} \mathrm{C} / \mathrm{min}$ from $10{ }^{\circ} \mathrm{C}$ down to $-90{ }^{\circ} \mathrm{C}$. This protocol corresponds to the optimal one to characterize the glass transition domain. We could precise that all the calorimetric curves were normalized to the NR weight. 


\section{RESULTS AND DISCUSSION}

The DSC curves are presented in Figure 1. As usually observed for rubber systems, the glass transition signature from DSC investigations is not clear, even if a change in baseline (baseline step) can be observed around $-65^{\circ} \mathrm{C}$ proving the existence of glass transition region as drawn in Figure 1. However, it is not possible to estimate with good accuracy the parameters characterizing the glass transition from these experiments, i.e. the glass transition temperature $\mathrm{T}_{\mathrm{g}}$ and the heat capacity step at $\mathrm{T}_{\mathrm{g}}$ noted $\Delta \mathrm{Cp}_{(\mathrm{Tg})}$. That is why we performed MT-DSC experiments. The curves obtained by this way are presented in Figures 2 and 3. We may note that the Rev Cp plots correspond to the heat capacity values of the samples. Thus, it is now possible to estimate with a very good accuracy the values characterizing the glass transition domain. All these values are given in Table 1. From the equation 1, it is possible to calculate the CRR size and all the necessary values are extracted from experimental data presented in Figures 2 and 3. We may note that $\mathrm{T}_{\alpha}$ corresponds to the temperature at the peak maxima in Figure 3, and $\delta \mathrm{T}$ is proportional to the width at the middle height of these peaks. Details about $\delta \mathrm{T}$ extraction are given in [13]. The $\mathrm{N}_{\alpha}$ values are given in Table 1.

Concerning the variations in $\mathrm{T}_{\alpha}$, we clearly observed an increase for the micro-composite and for all the nanocomposites. In this case, the molecular mobility at the glass transition is alleviated by the presence of filler in comparison to the neat NR sample. $\Delta \mathrm{C}_{\mathrm{p}}\left(\mathrm{T}_{\alpha}\right)$ values being quasi constant, we can conclude the amorphous content remains constant whatever the content and the filler nature. 


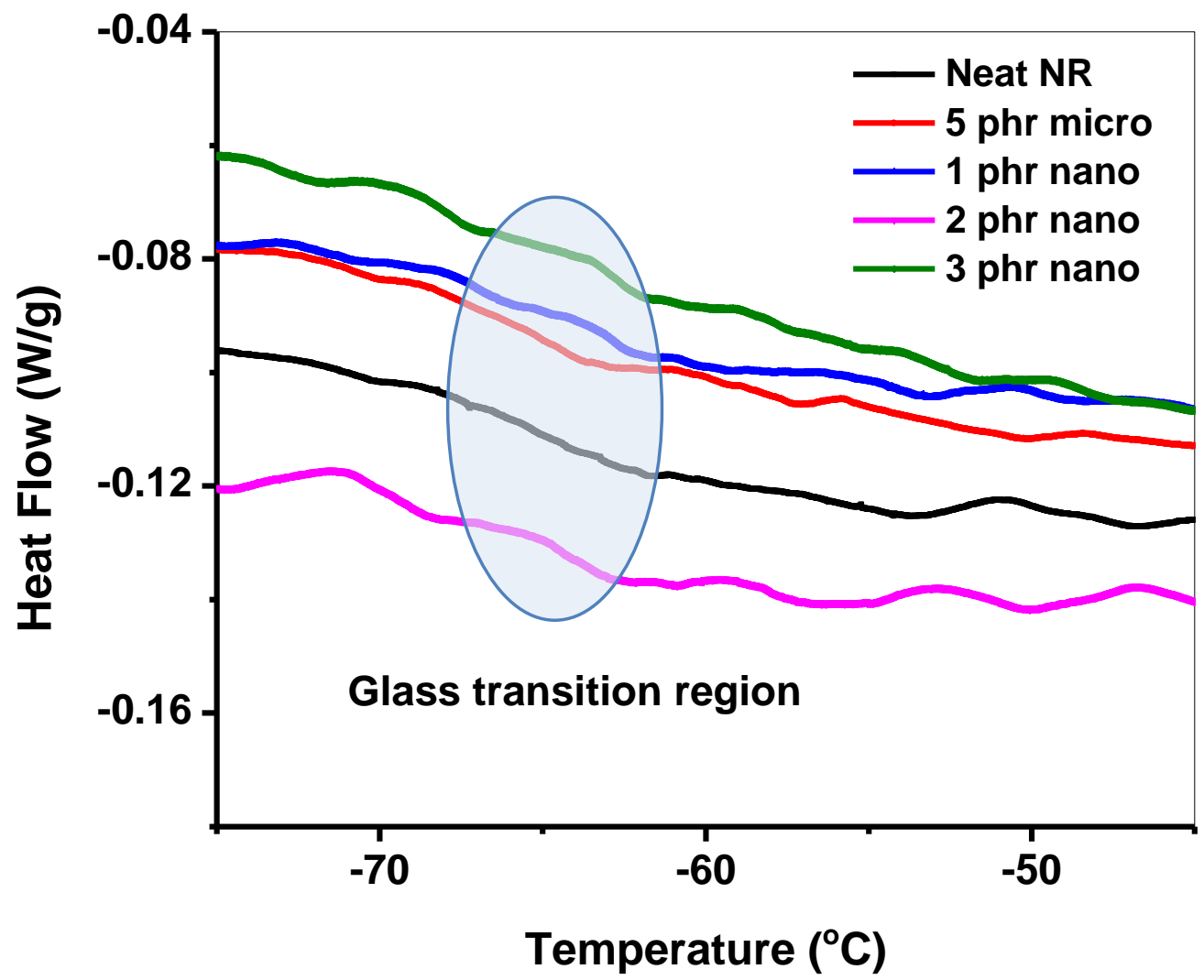

Figure 1.Heat Flow curves obtained by classical DSC for neat NR and the different composites 


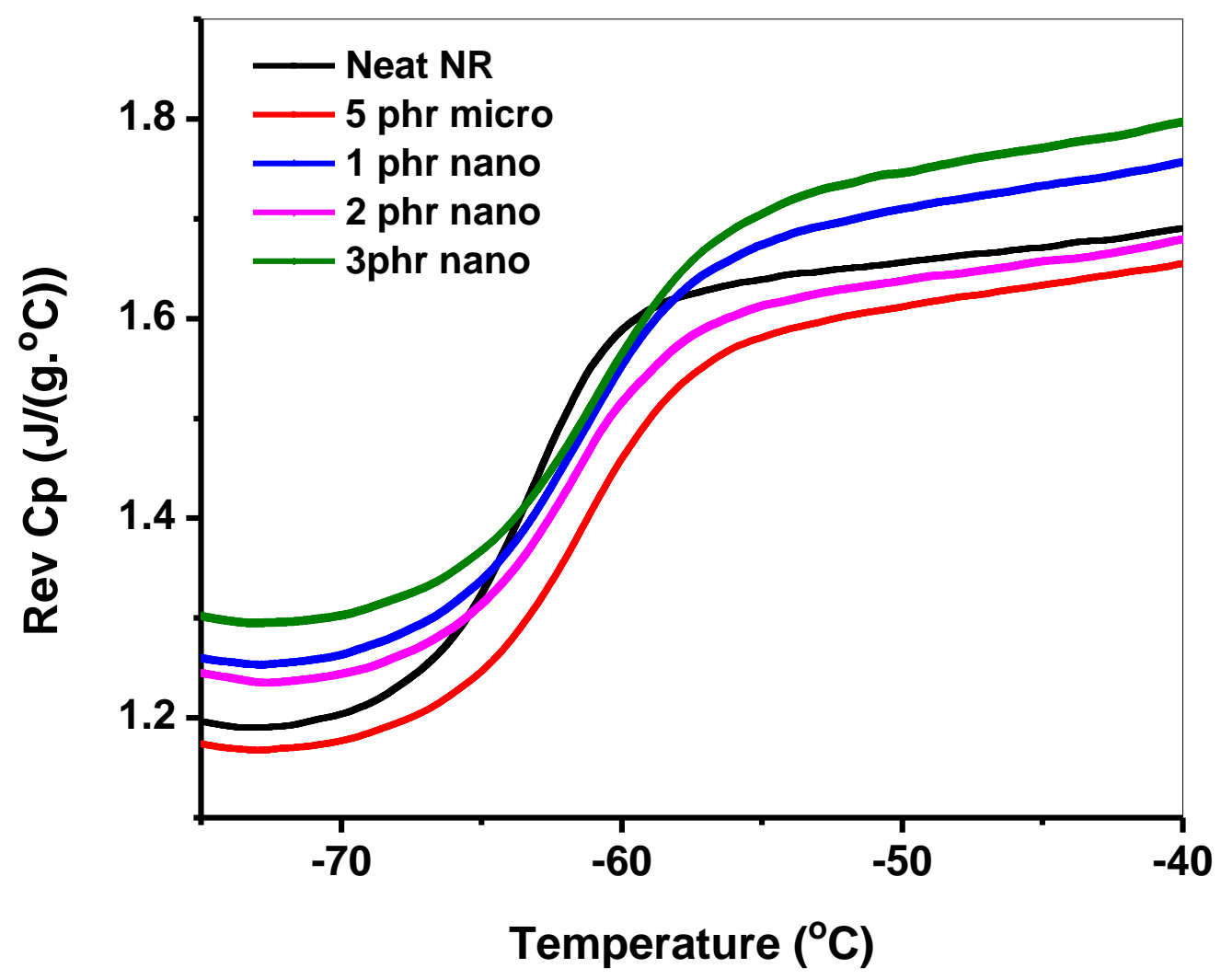

Figure 2. Reversing Cp curves obtained by MT-DSC experiments for neat NR and the different composites 


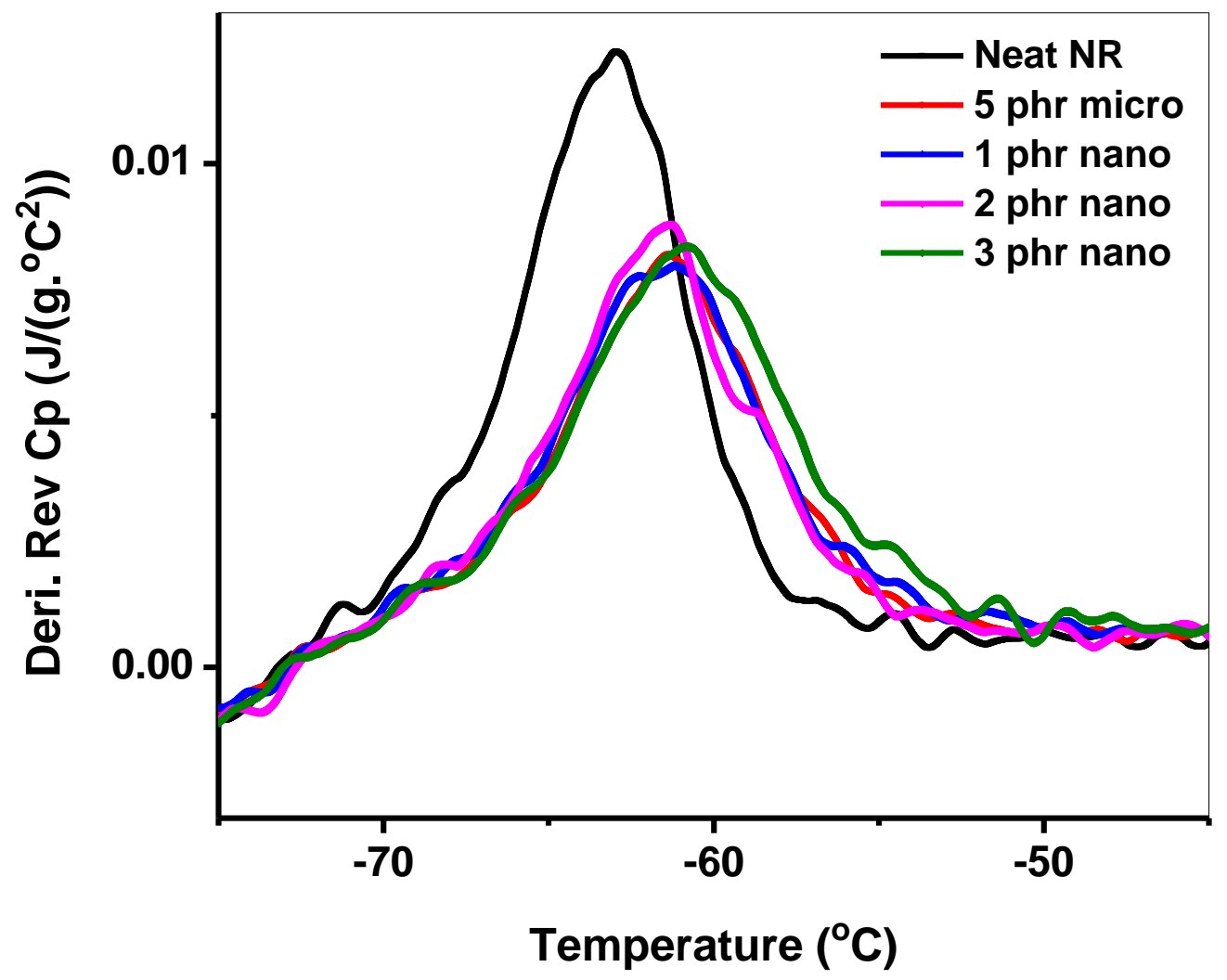

Figure 3. Derivative of the Reversing Cp curves obtained by MT-DSC experiments for neat NR and the different composites

Table 1. Values of the glass transition temperature $T_{\alpha}$, the heat capacity step at $T_{\alpha}$ $\Delta \mathrm{Cp}_{(\mathrm{T} \alpha)}$, the number of structural units per $\mathrm{CRR} \mathrm{N}_{\alpha}$, the constrained volume $\mathrm{C}_{\mathrm{v}}$, and the thickness of immobilized polymer layer at the interface $\chi_{\mathrm{m}}$ for neat NR and the different composites

\begin{tabular}{|c|c|c|c|c|c|}
\hline samples & $\mathrm{T}_{\alpha}\left({ }^{\circ} \mathrm{C}\right)$ & $\Delta \mathrm{Cp}_{(\mathrm{T} \alpha)}\left(\mathrm{J} /\left(\mathrm{g} .{ }^{\circ} \mathrm{C}\right)\right)$ & $\mathrm{N}_{\alpha}$ & $\mathrm{C}_{\mathrm{v}}(\%)[12]$ & $\chi_{\mathrm{m}}(\mathrm{nm})$ \\
\hline Neat NR & $-63.5 \pm 0.5$ & $0.39 \pm 0.02$ & 188 & 0.0 & 0.0 \\
\hline NR-5phr micro & $-61.5 \pm 0.5$ & $0.35 \pm 0.02$ & 119 & -- & 0.058 \\
\hline NR-1 phr nano & $-61.5 \pm 0.5$ & $0.37 \pm 0.02$ & 112 & 9.5 & 0.042 \\
\hline NR-2 phr nano & $-62.0 \pm 0.5$ & $0.32 \pm 0.02$ & 105 & 17.6 & 0.163 \\
\hline NR-3 phr nano & $-61.0 \pm 0.5$ & $0.34 \pm 0.02$ & -- & 4.8 & 0.102 \\
\hline
\end{tabular}


Table 2. Tensile Strength, Tensile Modulus, Elongation at the Break of rubber nanocomposites [12]

\begin{tabular}{|c|c|c|c|}
\hline samples & $\begin{array}{c}\text { Tensile strength } \\
(\mathrm{MPa})\end{array}$ & $\begin{array}{c}\text { Tensile Modulus } \\
(\mathrm{MPa}) 300 \%\end{array}$ & $\begin{array}{c}\text { Elongation at } \\
\text { the break (\%) }\end{array}$ \\
\hline Neat NR & 2.04 & 0.47 & 801 \\
\hline NR-1 phr nano & 18.17 & 0.87 & 1403 \\
\hline NR-2phr nano & 25.56 & 2.28 & 637 \\
\hline NR-3phr nano & 6.68 & 1.37 & 873 \\
\hline
\end{tabular}

Table 2 gives the evolution of the mechanical properties (Tensile strength, Tensile Modulus, Elongation at the break) for nanocomposites in comparison to neat NR sample. The tensile strength and tensile modulus increase with the addition of the nano $\mathrm{ZnO}$ from 1 to $2 \mathrm{phr}$, and decrease on further addition (i.e. $3 \mathrm{phr}$ ) of nano $\mathrm{ZnO}$; whereas the elongation at the break of rubber nanocomposites decreases from 1 to $2 \mathrm{phr}$ of nano $\mathrm{ZnO}$, and increases on further addition (i.e. 3 phr) of nano $\mathrm{ZnO}$. A comparison of the reported mechanical properties of the NR-micro ZnO filled composite [23] with that of NR-2 phr nanocomposite shows that about $27 \%$ enhancement in the tensile strength, $78 \%$ enhancement in the modulus (300\%), and $48 \%$ decrease in the elongation at the break were observed for the NR-2 phr nanocomposite. The decrease in the value of tensile strength and tensile modulus for NR-3 phr nanocomposite is due to the aggregation of nanoparticles at higher nanofiller concentration as evidenced from TEM images (Figures 4 a,b) [12]. The enhancement of mechanical properties of nanocomposites can be attributed to the homogeneous dispersion of nano $\mathrm{ZnO}$, and strong nanofiller-rubber matrix interactions exist in them. For NR-3 phr nanocomposite, filler-filler interaction is more pronounced than nanofiller-rubber matrix interactions. 
(a)

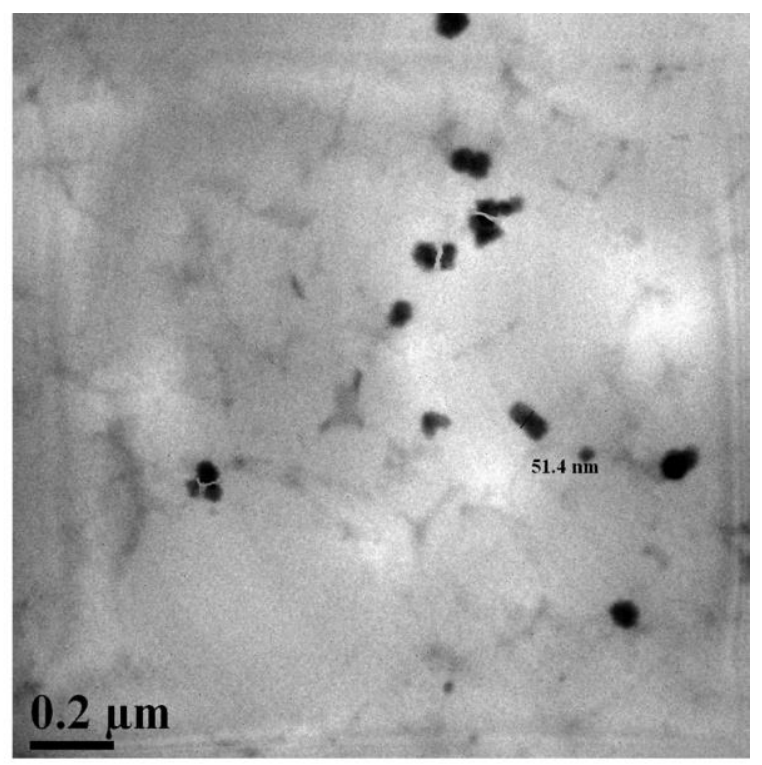

(b)

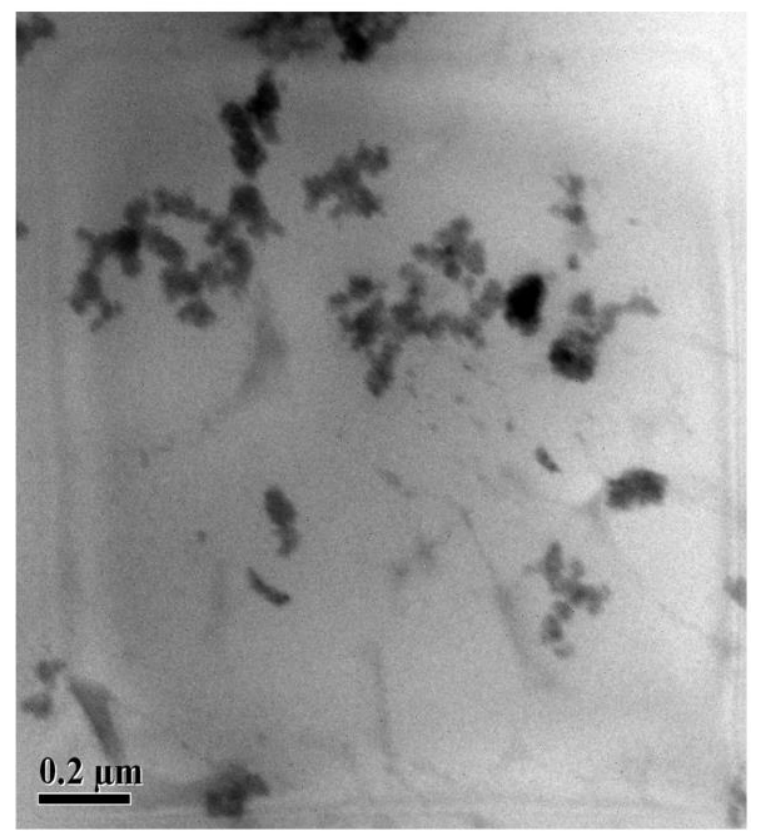

Figure. 4(a) TEM image of NR-2 phr nano (b)TEM image of NR-3 phr nano [12]

Considering the CRR size evolution, the value obtained for the micro composite (i.e. NR-5 phr micro) in comparison with neat NR proves the decrease of the cooperativity due to the presence of filler $\left(\mathrm{N}_{\alpha}\right.$ significantly decreases from 188 down to 119), despite the less increase in terms of glass transition temperature (from $-63,5^{\circ} \mathrm{C}$ up to $-61,5^{\circ} \mathrm{C}$ ). Indeed with $5 \mathrm{phr}$ of microfiller, there are greater interactions between filler and matrix inducing the CRR decrease, but the presence of microfiller hampers the chain mobility, involving a low $\mathrm{T}_{\alpha}$ increase. Concerning the nanocomposites, as for NR-3 phr nanocomposite aggregations of nanoparticles have been evidenced from TEM images (Figure 4b), we only compare the evolution between neat NR and nanocomposites up to $2 \%$ of filler. We may note the higher the wt. $\%$ of nanofiller, the lower 
the CRR size, proving that the filler-matrix interactions are more and more pronounced. From the CRR size values, it seems the best nanocomposite in terms of filler/matrix interactions is NR-2 phr nano. As reported in our previous work, $\mathrm{ZnO}$ acts as a cure activator in rubber compounds: instead of $5 \mathrm{phr}$ of micro $\mathrm{ZnO}, 2 \mathrm{phr}$ of nano $\mathrm{ZnO}$ is sufficient to bring the properties of $5 \mathrm{phr}$ of micro $\mathrm{ZnO}$ in NR composites [12]. Furthermore, the best mechanical properties are observed for $2 \mathrm{phr}$ of nano $\mathrm{ZnO}$ sample due to the stronger interactions between filler and matrix. Then, the predictions related to the CRR size seems to be in good agreement with the previous work [12].

DMA was performed to investigate the nature of the constrained polymer region in NR matrix. The segmental motion of rubber chains is progressively restricted when nano $\mathrm{ZnO}$ particles are homogeneously dispersed in the rubber matrix and hence the volume of the constrained rubber chains $\left(\mathrm{C}_{\mathrm{v}}\right)$ also increases as in the case of NR-1 phr nanocomposite and NR-2 phr nanocomposite. The constrained polymer region is the significant factor which establishes the reinforcement mechanism in NR nanocomposites. Moreover, as shown in Table 1, the constrained volume values noted $\mathrm{C}_{\mathrm{v}}$ and calculated from DMA investigations [12] are inversely proportional to the CRR size for NR-1 phr nanocomposite and NR-2 phr nanocomposite, proving the correlation of the CRR size evolution with macroscopic properties like mechanical ones.

It is well established that the presence of nanoparticles in a polymer network would create entangled or constrained state of the polymer chains. More precisely, when nanoparticles are incorporated in amorphous polymers viz. elastomers, the mobile amorphous chains in the original polymer are changed into two components viz. mobile and rigid amorphous components (Schemes 1a, b). Several research reports revealed that the presence of a very thin layer (a few nanometers of thickness) of interfacial polymer with restricted mobility is detected around the filler particles, while the rest of the polymer follows bulk dynamics [24]. 


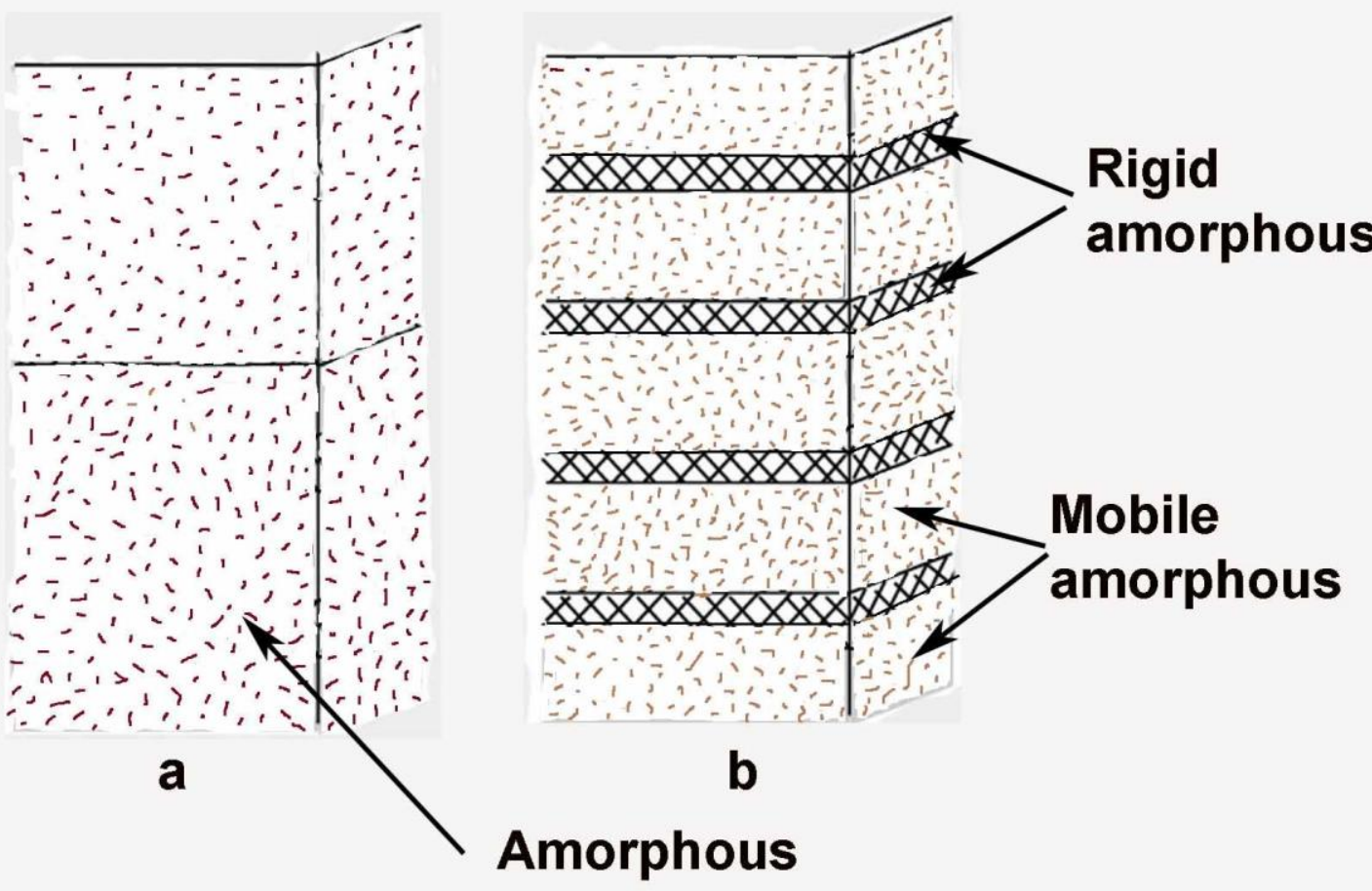

Scheme 1a. Formation of rigid amorphous fractions in amorphous polymers: (a) before filler and (b) after the addition of nanofiller

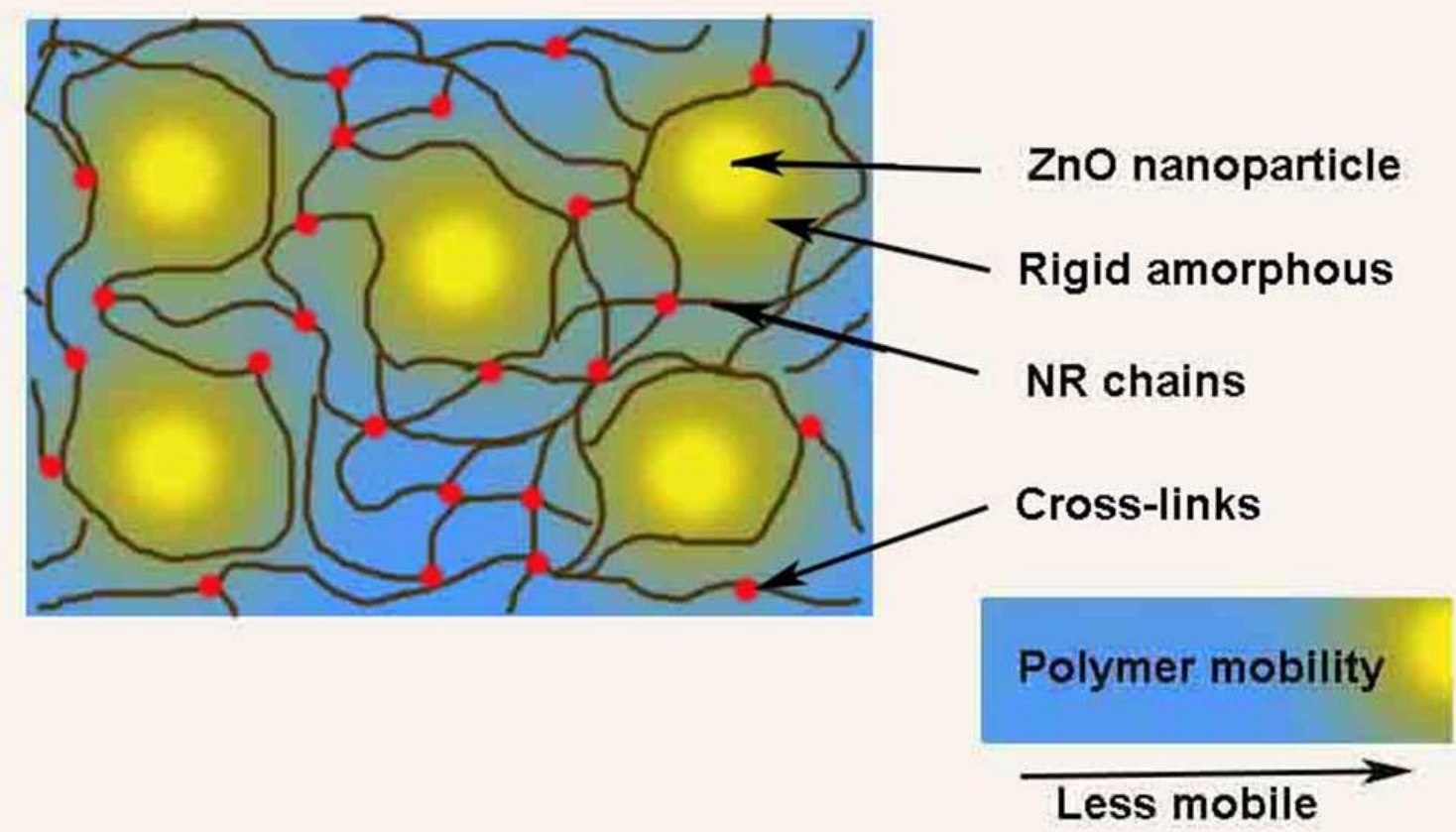

Scheme 1b. Immobilized polymer chains on the surface of $\mathrm{ZnO}$ nanoparticles forming a rigid amorphous part 
This aspect has been well explained in various models viz. three-layer models [25], two-layer models $[24,26]$ or a continuous distribution of glass transition temperatures as a function of distance from the particle surface [27]. The nature and behavior of the polymer-filler interface can create a major influence on the macroscopic properties. Moreover, studies revealed that different segmental mobility have been observed close to the filler surface, where segmental relaxation times are significantly longer than those of the unfilled polymer [28].

But in nanocomposites due to strong polymer-filler interactions, the amorphous content is supposed to change to mobile and rigid amorphous portions [29]. In the present case, NR has no affinity towards $\mathrm{ZnO}$, unless the presence of a coupling agent; it acts as a cure activator in the sulphur vulcanization and curing process [12]. The interaction of the polymer chains with the filler particles surface is a kind of secondary interactions viz. weak Van der Waals forces [12]. Based on the above reports, it was understood that the polymer chains are immobilized in the rigid amorphous content by the filler surface. So, $\Delta \mathrm{Cp}$ measurements can be used as a tool to predict the rigid amorphous content of the nanocomposites [20,30].

Figure 5 presents the variations of the $\Delta \mathrm{Cp}$ or normalized heat capacity $\Delta \mathrm{Cp} / \Delta \mathrm{Cp}{ }^{0}$ with wt. $\%$ of $\mathrm{ZnO}$, where $\Delta \mathrm{Cp}^{0}$ is the heat capacity of the $\mathrm{NR}$, and $\Delta \mathrm{Cp}$ the heat capacity value ofeach nanocomposite given in Table 1 . The $\Delta \mathrm{Cp}$ or normalised $\Delta \mathrm{Cp}$ values show a drastic decrease from the reference line (additivity line) indicating strong polymer-filler interaction. The $\Delta \mathrm{Cp}$ or normalized heat capacity $\Delta \mathrm{Cp} / \Delta \mathrm{Cp}^{0}$ value decreases with wt. $\%$ of $\mathrm{ZnO}$ and this can be explained in terms of the formation of an immobilized layer of polymer around the filler particles. The fraction of immobilized polymer can then be calculated by the following equation:

$\chi_{\mathrm{m}}=1-\frac{\Delta \mathrm{C}_{\mathrm{p}}}{\Delta \mathrm{C}_{\mathrm{p}}^{0}\left(1-\mathrm{W}_{\mathrm{ZnO}}\right)}$

Where $\mathrm{W}_{\mathrm{ZnO}}$ is the weight fraction of $\mathrm{ZnO}$. The accuracy obtained on $\Delta \mathrm{Cp}$ measurements thanks to MT-DSC investigations allows us to estimate the fraction of immobilized polymer $\chi_{m}$ with a very good accuracy. The values obtained are given in Table 1 . The thickness of immobilized polymer layer increases with wt. $\%$ of $\mathrm{ZnO}$, it is revealed that the strongest rubbernano $\mathrm{ZnO}$ interactions are present in NR-2 phr nano $\mathrm{ZnO}$ composite. The reason for the enhanced mechanical properties is the strong rubber-nano $\mathrm{ZnO}$ interactions, proved from the calculated values of $\mathrm{C}_{\mathrm{v}}, \chi_{\mathrm{m}}$ and CRR size. As NR-3 phr nano $\mathrm{ZnO}$ nanocomposite exhibits agglomerated filler particles in the matrix (see Figure $4 \mathrm{~b}$ ) a lower value of constrained volume 
$\mathrm{C}_{\mathrm{v}}$ is obtained (Table 1), which establishes that more filler-filler interactions are pronounced in the composite than filler-polymer interactions.

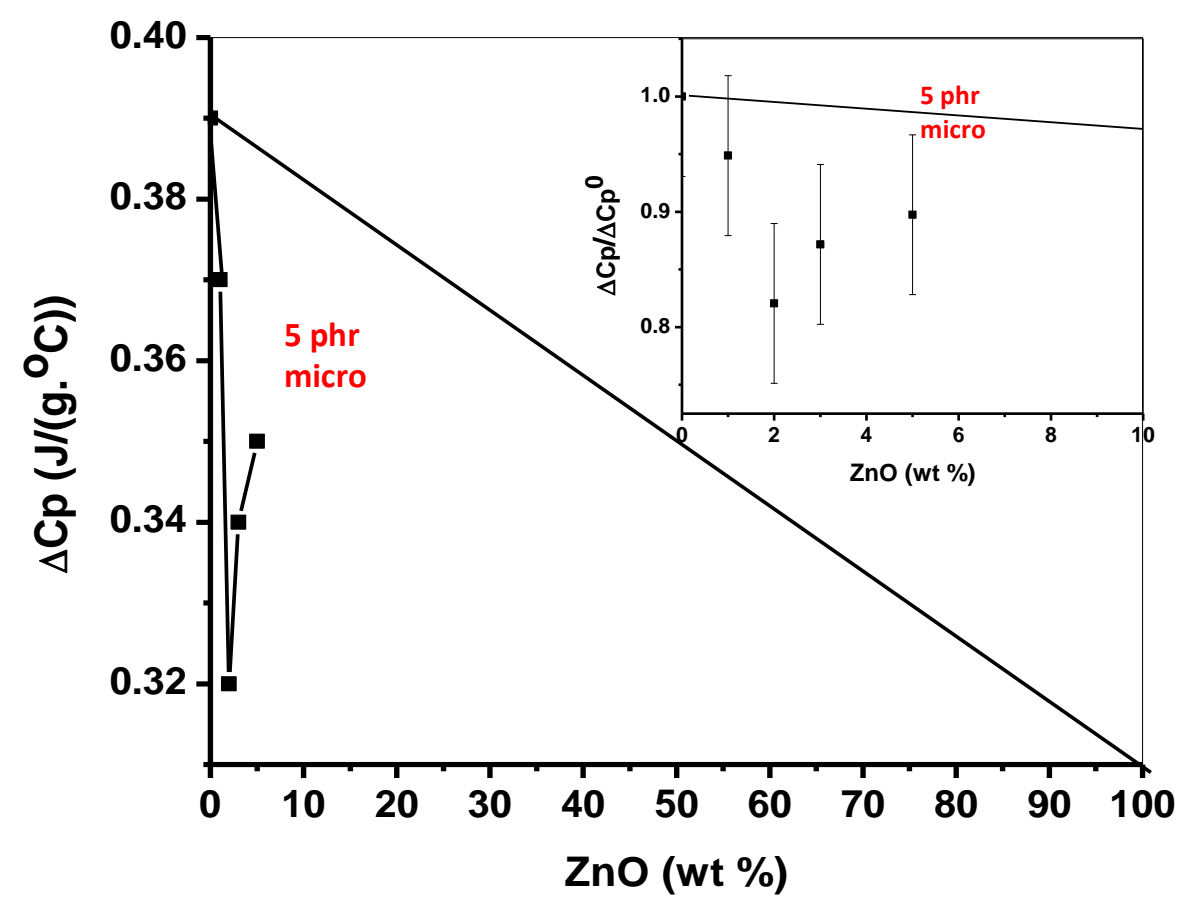

Figure 5. $\Delta \mathrm{C}_{\mathrm{p}}$ as a function of wt. $\%$ of $\mathrm{ZnO}$; insert: Normalised $\Delta \mathrm{C}_{\mathrm{p}}$ as a function of wt. $\%$ of $\mathrm{ZnO}$

\section{CONCLUSIONS}

In this work, the glass transition characteristics of NR composites, i.e. the glass transition temperature and the heat capacity step at this temperature, have been obtained with a very good accuracy through MT-DSC investigations in comparison to the classical DSC experiments. This work highlights the interest of using the Donth's approach as a probe for understanding the chain mobility in rubber systems. Indeed, we proved a good correlation between the CRR size evolution, and the evolution of the mechanical properties as a function of filler content: the lower the CRR size, the higher the fraction of immobilized polymer chains and stronger interactions between fillers and matrix, and hence the enhancement in the mechanical properties. Furthermore, the evolution of the CRR size at the glass transition in terms of number $\left(\mathrm{N}_{\alpha}\right)$ is consistent with the evolution of the constrained volume $\left(\mathrm{C}_{\mathrm{v}}\right)$ and the thickness of immobilized polymer chains at the interface $\left(\chi_{\mathrm{m}}\right)$ measured at the same temperature for nanocomposites with homogeneous dispersion of $\mathrm{ZnO}$ nanoparticles: the lower the $\mathrm{N}_{\alpha}$ value, 
the higher the $C_{v}$ and $\chi_{m}$ values. Thus, the Donth's approach is a powerful probe to estimate the enhancement of mechanical properties in nanocomposites from calorimetric investigations.

\section{ACKNOWLEDGEMENTS}

The authors are grateful to the European Union and the Normandy Region for the financial support given to the MAGMA project via the "Fonds Européen de Développement Régional" (FEDER).

\section{REFERENCES:}

1 L. Bokobza, Nanomaterials 9 (2019) 12.

2 M. Jun, X. Ping, M. Yiu-Wing, and Z. Zi-Qun, Macromol. Rapid Commun.25 (2004) 1692.

3 M. Galimberti, S. Senatore, L. Conzatti, G. Costa, G. Giuliano, and G. Guerra, Polym. Adv. Technol. 20 (2009) 135.

4 Y. R. Liang, J. Ma, Y.L. Lu, Y.P.Wu, L.Q. Zhang, and Y.W. Mai, J. Polym. Sci. Polym. Phys. 43 (2005) 2653.

5 K. P. Surya, S. Bhattacharya, R. Mukhopadhyay, K. Naskar, and A.K. Bhowmick, Rubber Chem. and Technol., January 2020, DOI: 10.5254/rct.20.80424.

6 E. Mastalygina, I. Varyan, N. Kolesnikova, M. I. C. Gonzalez and A. Popov, Polymers $12,(2020) 437$.

7 I. Yuko, K. Atsushi, S. Junichi, and K. Shinzo, Macromol. Rapid Commun. 25 (2004) 1186.

8 J. N. Coleman, U. Khan, W. J. Blau, and Y. K. Gunko, Carbon 44 (2006) 1624.

9 C. G. Robertson, and C. M. Roland, Rubber Chem. Technol. 81 (2008) 506.

10 Y. Liu, J. Gao, Y. Wang, J. Zhou, L. Cao, Z. He, Y. Zhang, C. Tang, and L. Zhong, Macromol. Rapid Commun. 2019, 1900406.

11 Y. Jin, X. Zheng, Lu Wan, J. Chen, C. Wang, B. Li, J. Appl. Polym. Sci. 2020; e49225. https://doi.org/10.1002/app.49225.

12 P. Bindu, and S. Thomas, J. Phys. Chem. B, 117(41) (2013) 12632-12648.

13 E. Donth, J. Non Cryst. Solids. 53, 325 (1982).

14 Adam, G, and J. H. Gibbs. J. Chem. Phys., 43 (1) (1965) 139.

15 S. S. Ray, and M. Okamoto, Prog. Polym. Sci. 28 (2003) 1539.

16 A. Saiter, H. Couderc, and J. Grenet. J. Therm. Anal. Cal. 88 (2007) 483.

17 H. Couderc, L. Delbreilh, A. Saiter, J. Grenet, N. De Souza, J.M. Saiter, J. Of Non Cryst. Solids 353 (2007) 4334. 
18 A. N. Khan, P. D. Honga, W. T. Chuang, and K. S. Shih, Polymer 50 (2009) 6287.

19 H. Couderc, A. Saiter, J. Grenet, and J. M. Saiter, Physica B. 406 (2011) 2908.

20 A. Saiter, N. Delpouve, E. Dargent, W. Oberhauser, L. Conzatti, F. Cicogna, E. Passaglia, Eur. Polymer Journal 78 (2016) 274.

21 P. Bindu, S. Thomas, J. Theor. Appl. Phys. 8141 (2014) 1.

22 Aswathy, K. V. Nano ZnO: A Novel Modifier for Thermoplastics, Ph.D. Thesis, Cochin University of Science \& Technology, Kochi-22, Kerala, India (2008).

23 Meera, A. P. Effect of Spherical and Layered Type Fillers on the Morphology and PhysicoMechanicl Properties of Natural Rubber Nanocomposites. Ph.D. Thesis, Mahatma Gandhi University, Kottayam, Kerala, India, 2010.

24 S.E. Harton, S.K. Kumar, H. Yang, T. Koga, K. Hicks, H. Lee et al. Macromolecules 43 (2010) 3415.

25 G.Tsagaropoulos, A. Eisenberg, Macromolecules,28 (1995) 6067.

26 A. Sargsyan, A. Tonoyan, S. Dactyan, C. Schick, EurPolym J 43 (2007) 3113.

27 J. Berriot, H. Montes, F. Lequeux, D. Long, P. Sotta, Macromolecules 35 (2002) 9756.

28 V. Arrighi, J.S. Higgins, A.N. Burgess, G. Floudas, Polymer 39 (1998) 6369.

29 Saliney Thomas, S.C. George, S. Thomas, Progress in Rubber, Plastics and Recycling Technology, 33 (2017) 103.

30 C. Schick, A. Wurm, A.Mohamed, Colloid Polym. Sci. 279 (2001) 800. 